\title{
2. CHLORIN AND PORPHYRIN GEOCHEMISTRY OF DSDP LEG 40 SEDIMENTS
}

\author{
E.W. Baker, S.E. Palmer, and W.Y. Huang, \\ Northeast Louisiana University, Department of Chemistry, Monroe, Louisiana
}

\section{INTRODUCTION}

Even thick sequences of sediments in marine depositional basins contain only limited segments of the record of chlorophyll diagenesis. Extracts from Pleistocene deep-sea sediments (Baker and Smith, 1973a) yielded extensive information concerning early chlorin transformations. Investigations of marine sediments of Pliocene and Miocene age resulted in the first reports of free base porphyrins occurring with nickel porphyrins and chlorins (Baker and Smith, 1975a; Smith and Baker, 1974). Initial studies of Pliocene, Eocene, and late Cretaceous marine sediments indicated the co-existence of nickel porphyrins and chlorins (Baker and Smith, 1975b). The characterization of late diagenetic products, the petroporphyrins, has previously been reported in Baker et al., 1967.

The present suite of samples from DSDP Sites 361 and 364 has yielded the most complete record of the free base-metalloporphyrin transition in an early Cretaceous setting known to date. These samples fill the gap between early diagenesis (Baker and Smith, 1973a) and late diagenesis (petroleum and bitumen).

Only until data such as these are obtained for each stage of chlorophyll diagenesis can statements concerning the relationships between tetrapyrrole structure and geological history of marine basins (including expression of oxidation-reduction state of the enclosing sediments, effect of thermal treatment and age/depth of burial) be made with a high degree of reliability.

The abundance of pigment in early Cretaceous samples permitted more extensive separation and purification techniques than was previously reported for DSDP samples. Separation of the pigments into nickel, vanadyl, and free base varieties and mass spectrometry of these fractions have provided important new insights into the distribution of the geoporphyrins. Compared to previous reports in which the total pigment was demetallated and subsequently subjected to mass spectrometric analysis, the present approach shows that many important differences exist among these fractions.

The most extensive mass spectral data yet obtained on metalloporphyrins in deep ocean sediments are reported here. These analyses extend and/or confirm previous ideas concerning the most probable middiagenetic pathway of chlorophyll and its derivatives (Baker and Smith, 1973b).

Nineteen samples ranging in age from Pleistocene to early Cretaceous from DSDP Sites 361-364 were examined for tetrapyrrole content. Sediments from Walvis Ridge (Site 362), ranging from Pleistocene to Miocene in age, contained chlorins with trace amounts of free base porphyrins present. The amount of chlorin decreased with increasing depth/geologic age consistent with previous reports. Early Cretaceous sediment samples from Site 361 (Cape Basin) and particularly Site 364 (Angola Basin) contained abundant nickel and vanadyl porphyrins in line with expectations for older organic-rich sediments. Free base porphyrins were found at Site 361 and 364 samples along with the two chelates. Site 363 samples were barren of pigment except for the oldest core (early Cretaceous) which contained a small amount of nickel porphyrin. Results from Site 356 (Leg 39) where small amounts of metalloporphyrins were found are included (see Table 1).

A small amount of a previously unrecognized metalloporphyrin was found in extracts from Site 364. Electronic spectral data, chromatographic behavior, and fluorescence characteristics show definitely that this metalloporphyrin is not a typical (nickel or vanadyl) chelate. Total characterization is not complete, but the data best fit that of a zinc chelate of a highly polar porphyrin ligand.

\section{EXPERIMENTAL PROCEDURE}

All core samples were stored frozen until analysis. Typically, $100 \mathrm{~g}$ of wet sediment were ball milled in acetone:methanol $(9: 1)$ until all traces of pigment were removed. The crude extracts were applied to $2.5 \times 20 \mathrm{~cm}$ chromatographic columns of Sephadex LH-20 and the pigments were eluted with THF. Each step in the isolation procedure was monitored by UV-visible spectrophotometry. Free base porphyrins were separated from metalloporphyrins by partition between $3 \mathrm{~N} \mathrm{HCI}$ and ether. The resulting pigment fractions were then chromatographed over $1 \times 10 \mathrm{~cm}$ Alumina Grade III chromatographic columns and eluted with cyclohexane, benzene, and mixtures of benzene and THF. This method allowed separation between two nickel porphyrin fractions having different polarities and between the nickel and vanadyl porphyrins which collectively have greater polarity than nickel porphyrins (nonpolar nickel:Cy $\mathrm{C}_{6}$; polar nickel: $\mathrm{Cy} \mathrm{C}_{6}$ $\mathrm{Bz}, 50-50$ to 0-100; vanadyl:Bz-THF, 100-1 to 50-50). Large amounts of impurities, probably condensed-ring aromatics, less polar than nickel porphyrins, were removed initially with cyclohexane.

The UV-visible spectrum of each pigment fraction was recorded (Table 1) using a Beckman ACTA CIII ultraviolet-visible scanning spectrophotometer. Mass 
TABLE 1

Tetrapyrrole Pigments in Core Samples From Leg 40

\begin{tabular}{|c|c|c|c|c|c|c|c|c|c|c|c|c|c|c|}
\hline \multirow{2}{*}{$\begin{array}{l}\text { Section } \\
361-5-4 \\
361-23-3\end{array}$} & \multirow{2}{*}{$\begin{array}{l}\text { Geologic Age }^{\mathrm{a}} \\
\text { Early Eocene }\end{array}$} & \multirow{2}{*}{$\begin{array}{c}\begin{array}{c}\text { Depth of } \\
\text { Burial }^{\mathrm{a}} \\
(\mathrm{m})\end{array} \\
174-183.5\end{array}$} & \multirow{2}{*}{$\begin{array}{c}\begin{array}{c}\text { Organic } \\
\text { Carbon }^{\mathrm{a}} \\
\text { (\% by wt) }\end{array} \\
0.14^{\mathrm{C}} \\
1.07-44\end{array}$} & \multirow{2}{*}{$\begin{array}{c}\begin{array}{c}\text { Individual } \\
\text { Yield } \\
\text { (ug/g) }\end{array} \\
\text { Trace } \\
\text { None }\end{array}$} & \multicolumn{9}{|c|}{$\begin{array}{l}\text { UV-Visible Absorption Spectra } \\
\text { (nanometers) }\end{array}$} & \multirow{2}{*}{$\begin{array}{l}\text { Pigment Type } \\
\text { Chlorin }\end{array}$} \\
\hline & & & & & 391 & & & & 550 & 577 & & & 656 & \\
\hline \multirow{3}{*}{$361-31-2$} & Early Cretaceous & $1048-1057.5$ & $294-1175$ & 0.42 & 409.5 & & & & & & & & & $\begin{array}{l}\text { No pigment } \\
\text { Y }\end{array}$ \\
\hline & & & & 0.49 & 394 & & 514 & 533 & 551 & 572.5 & & & & $\begin{array}{l}\text { Vanadyl porphyrin } \\
\text { Nickel porphyrin }\end{array}$ \\
\hline & & & & 0.03 & $398-9$ & 498 & & 528 & & 566 & & 618 & & Free base porphyrin \\
\hline \multirow[t]{3}{*}{$361-34-4$} & Early Cretaceous & $1076.5-1086$ & $4.47 \cdot 7.31$ & 1.29 & 409.5 & & & 533 & & 572.5 & & & & Vanadyl porphyrin \\
\hline & & & & 0.21 & 390 & & 513 & & 551 & & & & & Nickel porphyrin \\
\hline & & & & Trace & $398-9$ & 498 & & 528 & & 566 & & 618 & & Free base porphyrin \\
\hline \multirow[t]{2}{*}{$361-38-2$} & Early Cretaceous & $1114.5-1124$ & $2.49-2.68$ & 0.05 & 409.5 & & & 533 & & 572.5 & & & & Vanadyl porphyrin \\
\hline & & & & $\begin{array}{l}0.006 \\
0.25^{\mathrm{d}}\end{array}$ & 393 & & 513 & & 550 & & & & & Nickel porphyrin \\
\hline \multirow[t]{2}{*}{$361-42-0$} & Early Cretaceous & $1181-1190.5$ & $3.61-1.03$ & 0.05 & 409.5 & & & 533 & & 572.5 & & & & Vanadyl porphyrin \\
\hline & & & & $\begin{array}{l}0.04 \\
0.09^{\mathrm{d}}\end{array}$ & 390 & & 514 & & 551 & & & & & Nickel porphyrin \\
\hline \multirow[t]{3}{*}{$362-1-5$} & Pleistocene & $36-45.5$ & $5.05-3.32$ & 3.69 & 407.5 & 495 & & 532 & & & 602 & & 661 & Chlorin \\
\hline & & & & 3.64 & 407.5 & 495 & & 530 & & & 603 & & 660 & Chlorin \\
\hline & & & & 2.96 & 401 & 498 & & 530 & & & 597 & & 658 & Chlorin \\
\hline \multirow[t]{4}{*}{$362-7-5$} & Early Pleistocene & $93-102.5$ & $2.15 \cdot 2.89$ & 1.21 & 400 & 495 & & 532 & & & 600 & & 661 & Chlorin \\
\hline & & & & 0.62 & 400 & 495 & & $(532)$ & & & 600 & & 658 & Chlorin \\
\hline & & & & 0.94 & 397 & 495 & & 530 & & (567) & (573) & & 641658680 & Chlorin \\
\hline & & & & 0.32 & 400 & 498 & & 530 & & 561 & & 618 & & Free base porphyrin \\
\hline \multirow{4}{*}{$362-11-5$} & Pliocene & $131-140.5$ & $1.78-2.59$ & 0.41 & 401 & 495 & & 530 & & & 600 & & 660 & Chlorin \\
\hline & & & & 0.48 & 397 & 495 & & & & & 598 & & 658 & Chlorin \\
\hline & & & & 0.84 & 395 & 496 & & 525 & & 565 & & & 643656 & Chlorin \\
\hline & & & & 0.58 & 400 & 498 & & 530 & & 561 & & 618 & & Free base porphyrin \\
\hline \multirow[t]{3}{*}{$362-17-5$} & Late Miocene & $216.5-226$ & $1.13-0.63$ & 0.08 & 402 & 500 & & (535) & & & $(600)$ & & 659 & $\begin{array}{l}\text { Chlorin } \\
\text { Pats }\end{array}$ \\
\hline & & & & 0.08 & 395 & 500 & & (535) & & & 595 & & $658(690)$ & Chlorin \\
\hline & & & & 0.17 & 392 & 497 & & 527 & 554 & & 580 & & 660 & Chlorin \\
\hline \multirow[t]{3}{*}{$362-25-4$} & Middle Miocene & $368.5-378$ & $0.52-0.68$ & 0.03 & 400 & & & & & & (596) & & 658 & Chlorin \\
\hline & & & & 0.05 & 395 & & & & & & 597 & & 656 & Chlorin \\
\hline & & & & 0.04 & 392 & & & & 555 & & 582 & & 656 & Chlorin \\
\hline $363-1-4$ & Early Miocene & $31-40.5$ & $0.07^{\mathrm{c}}$ & None & & & & & & & & & & No pigment \\
\hline $363-5-4$ & Middle Oligocene & $107-116.5$ & $0.06^{\mathrm{c}}$ & None & & & & & & & & & & No pigment \\
\hline $363-9-3$ & Late Eocene & $183-192.5$ & $0.06^{\mathrm{c}}$ & None & & & & & & & & & & No pigment \\
\hline $363-18-4$ & Late/middle & $\sim 330$ & & None & & & & & & & & & & No pigment \\
\hline $363-23-1$ & $\begin{array}{l}\text { Paleocene } \\
\text { Late Cretaceous }\end{array}$ & $382.5-392$ & $0.07^{\mathrm{c}}$ & None & & & & & & & & & & No pigment \\
\hline $363-39-2$ & Early Cretaceous & $686.5-696$ & $0.03-0.05$ & 0.02 & 390 & & 515 & & 550 & & & & & Nickel porphyrin \\
\hline \multirow{3}{*}{$364-41-3$} & Early Cretaceous & $1005-1014$ & $0.63-5.45$ & & 409.5 & & & 533 & & 572.5 & & & & Vanadyl porphyrin \\
\hline & & & & ${ }_{0.09}^{\text {d }}$ & 394 & & 514 & & 551 & & & & & Nickel porphyrin \\
\hline & & & & 44. & $\begin{array}{l}400 \\
4035\end{array}$ & 498 & & $\begin{array}{l}530 \\
536\end{array}$ & & $\begin{array}{l}561 \\
569\end{array}$ & & 618 & & $\begin{array}{l}\text { Free base porphyrin } \\
\text { Unidentified metalloporphyrin }\end{array}$ \\
\hline \multirow[t]{4}{*}{$364-43-1$} & Early Cretaceous & $1033.5-1043$ & $6.51-0.17$ & 3.25 & 409.5 & & & 533 & & 572.5 & & & & Vanadyl porphyrin \\
\hline & & & & 0.19 & 394 & & 514 & & 551 & & & & & Nickel porphyrin \\
\hline & & & & 0.36 & 400 & 498 & & 530 & & 561 & & 618 & & Free base porphyrin \\
\hline & & & & e & 403.5 & & & 536 & & 569 & & & & Unidentified metalloporphyrin \\
\hline $356-17-0^{f}$ & Paleocene $\mathrm{f}^{\mathrm{f}}$ & $298.4^{f}$ & $0.38^{\mathrm{f}}$ & Trace & 392 & & & & & & & & & $\begin{array}{l}\text { Metalloporphyrin } \\
\end{array}$ \\
\hline
\end{tabular}

Data obtained from Leg 40 Summary.

bPigment yield calculated by using the following molar extinction coefficients: pheophytin "a" $=63700$ at $660 \mathrm{~nm}$, free base porphrin $=6540$ at $6.18 \mathrm{~nm}$, nickel porphyrin $=34820$ at 550 and vanadyl porphyrin $=26140$ at $572 \mathrm{~nm}$.

${ }^{c}$ Data obtained from DSDP, 08/28/75.

${ }^{\mathrm{d}}$ Polar nickel porphyrin.

${ }^{\mathrm{e}}$ Not calculated

f Data obtained from Leg 39 Summary based on $356-17-3$ core interval. 
spectrometric analyses were made on the free base and metalloporphyrins using a DuPont 21-491-BR mass spectrometer equipped with a solid sample probe inlet system. As the probe temperature (source temperatures were kept $5^{\circ}-10^{\circ}$ above that of the probe) was increased, the nonporphyrin contaminants were vaporized initially with porphyrin peaks appearing with increasing amplitude as the run progressed. Probe temperatures ranged from $235^{\circ}$ to $260^{\circ} \mathrm{C}$ for the free base porphyrins, $220^{\circ}$ to $270^{\circ} \mathrm{C}$ for nickel porphyrins, and $235^{\circ}$ to $270^{\circ} \mathrm{C}$ for vanadyl porphyrins.

Signal to noise $(\mathrm{S} / \mathrm{N})$ ratios of $15-20$ to 1 , using the intensity of the base peaks as a reference, are desirable. However, some information can be extracted from spectral peaks with a $\mathrm{S} / \mathrm{N}$ ratio as small as 2 to 1 . Approximately $2 \mu \mathrm{g}$ of highly purified pigment applied to the probe tips as previously described (Baker et al., in press) produce spectra of the desired quality $(\mathrm{S} / \mathrm{N}=20)$ in the cases of free-base and mono-isotopic $(\mathrm{V}=0)$ metal chelates. In cases of bi- and tri-isotopic metal chelates ( $\mathrm{Ni}$ and $\mathrm{Zn}$, respectively), the $\mathrm{S} / \mathrm{N}$ ratio is reduced accordingly.

For presentation of the mass spectrometric data (Table 2), the $\mathrm{m} / \mathrm{e}$ peak intensities (heights) were measured and then normalized. Peak intensities for the free base. vanadyl, and nickel porphyrins of the DPEP series were used directly in these calculations. However, spectrometric data obtained for nickel porphyrins of the etio series had to be corrected for the $\mathrm{Ni}^{60}$ isotope contribution from the corresponding nickel DPEP; i.e., both $\mathrm{C}_{32} \mathrm{H}_{34} \mathrm{~N}_{4} \mathrm{Ni}^{60}$ (DPEP) and $\mathrm{C}_{32} \mathrm{H}_{36} \mathrm{~N}_{4} \mathrm{Ni}^{58}$ (etio) have a molecular weight of 534. Deconvolution was accomplished by setting the value for the $\mathrm{Ni}^{58}$ DPEP peak intensity equal to 1 and then determining the value for the $\mathrm{Ni}^{\circ 0}$ DPEP peak (isotopic abundance of $\mathrm{Ni}^{58}=67.8 \% ; \mathrm{Ni}^{70}=26.2 \%$; ratio of $\mathrm{Ni}^{60}$ to $\mathrm{Ni}^{58}=0.38$ ). The $\mathrm{Ni}^{60}$ DPEP contribution was then subtracted from the peak intensity composed of $\mathrm{Ni}^{58}$ etio plus $\mathrm{Ni}^{60}$ DPEP. The corrected nickel etio peak intensities were then used to compute the normalized values in Table 2.

Chlorin-containing Sephadex fractions (typically 3 fractions were found, Table 1) were derivatized with diazomethane and then partitioned between $32 \% \mathrm{HCl}$ ethyl ether. Fractions selected for mass spectrometric analyses were then chromatographed on sugar with cyclohexane; benzene and ethyl ether used consecutively as eluants. Mass spectrometry of these chlorin fractions are incomplete at this time.

\section{RESULTS AND DISCUSSION}

\section{Chlorins}

Samples of Pleistocene through Miocene (Site 362) and Eocene (Core 361-5) in age contained chlorins which decreased in amount with increasing age/depth of burial. These pigments may be divided into two major fractions based on separation on Sephadex, sugar, and by their UV-visible spectra. For a diagramatic presentation of Sephadex chromatography see Baker and Smith (1973a). The first eluting (brownishgreen) Sephadex fraction contained chlorins with major UV-visible bands at $407.5 \mathrm{~nm}$ and $661 \mathrm{~nm}$ while a laterrunning dark olive-green fraction had a spectrum with major bands at $401 \mathrm{~nm}$ and $658 \mathrm{~nm}$. The later running chlorin fractions were less polar than the first-eluting fraction; this was demonstrated by the fraction behavior on powdered sugar chromatographic columns.

Taking Site 362 as an example, it is noted that in cores of successively increasing age and depth (Cores $362-1,-5,-7,-11,-17,-25)$ a trend in the absorption wavelength of the red band and the Soret band is noted. As the age ranges from Pleistocene, Pliocene, upper Miocene, to middle Miocene, both of these major absorption bands decrease by 3 and $7.5 \mathrm{~nm}$. respectively for the red band (661-658 $\mathrm{nm}$ ) and the Soret band (407.5-400 nm). Another trend with increasing depth/age of burial can be observed in Table 1. Older sediments (Pliocene, Miocene, Site 362 and Eocene, Site 361) had relatively more of the laterunning Sephadex fraction with shorter wavelength red band $(658$ to $656 \mathrm{~nm})$ than did Pleistocene sediments of Site 362 . The chlorin fraction of 361-5 (Eocene) was comprised only of those pigments with a $656-\mathrm{nm}$ red band. Table 2 also contains spectra for a chlorin fraction with intermediate Soret and red bands which may or may not represent mixtures of the first and laterunning fractions discussed above. The molecular changes responsible for these shifts are only partially understood. As pointed out in Smith and Baker (1974). increasing reduction of ring conjugating groups, such as the 9-keto and 2-vinyl substituents, causes a shift in the red band to shorter wavelengths. Therefore, the less polar dark olive-green fractions reported here may contain these kinds of chlorins. Only when the components which make up the total pigment mixture can be separated and analyzed will such information be available.

In two samples (362-7 and -17), chlorins with atypically long wavelength red bands $(680$ and $690 \mathrm{~nm})$ were found. Such pigments have been occasionally found in sediments of this age range (Baker and Smith, 1973a; Smith and Baker, 1974). We speculate that the chromophore responsible for this long-wavelength absorption results from an uncommon reduction mechanism acting on pheophytin "a" or a common reduction mechanism acting on a less common pheophytin.

A band at $641-643 \mathrm{~nm}$, which is generally associated with metallochlorins, was noted in 362-7 and -11. If these materials are native and not artifacts, they would represent a new class of geochlorins. On the basis of two samples such a conclusion would be highly premature, hence the nature of these pigments remains unresolved.

Mass spectra of chlorin samples are not available at this time. Because of the erratic behavior of geochlorins leading to irreversible destruction of the pigment fractions in the mass spectrometer source, a dependable procedure for recording mass spectra has not been available.

\section{Porphyrins}

Cretaceous samples from Sites 361 and 364 contained mixtures of nickel and vanadyl porphyrins with lesser amounts of free base porphyrins. UV-visible spectra of 
TABLE 2

Mass Spectral Data Obtained for Free Base, Nickel, and Vanadyl Porphyrins From Core Samples From Sites 361, 362, and 364

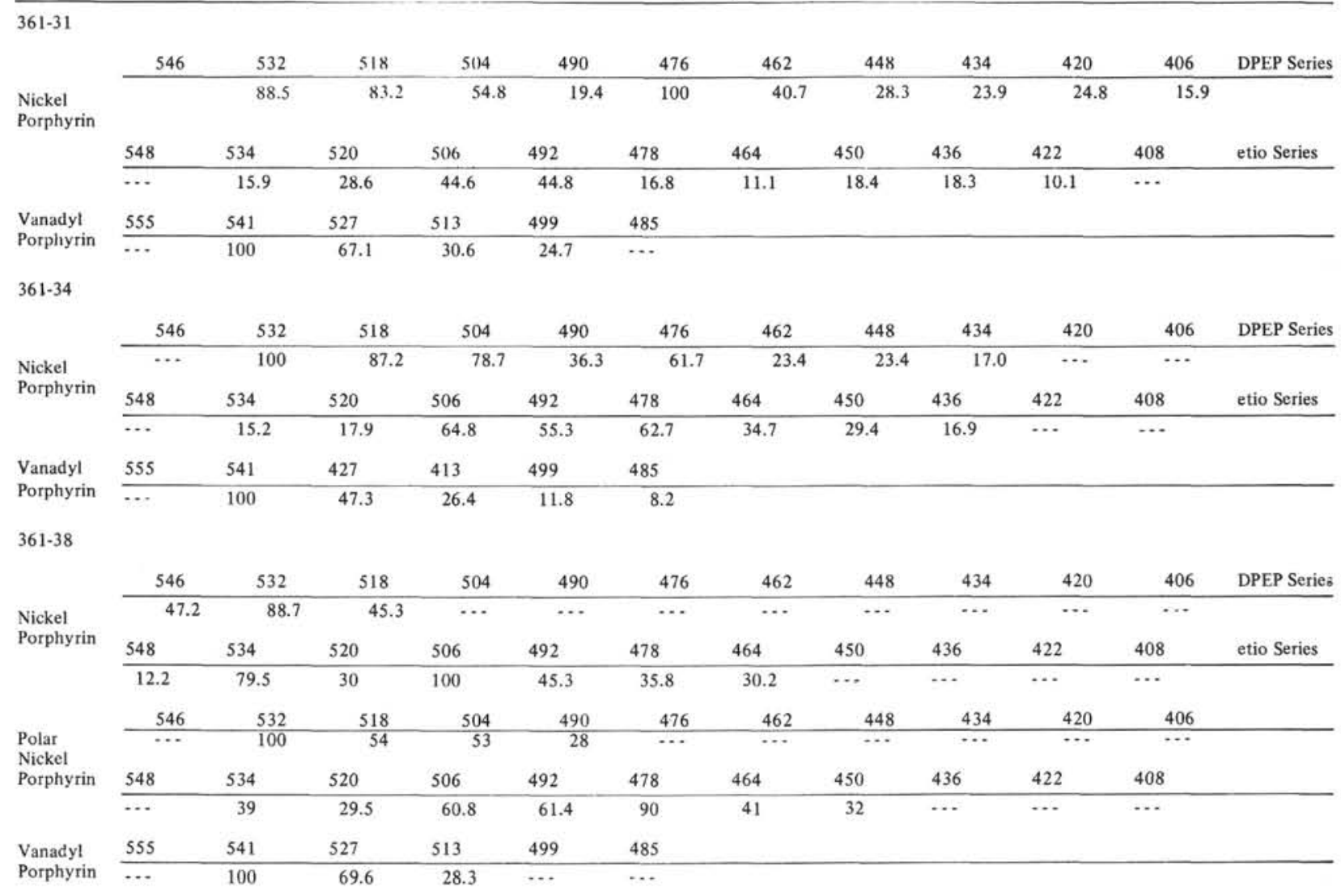

361-42

Nickel

\begin{tabular}{cccccccccccc}
546 & 532 & 518 & 504 & 490 & 476 & 462 & 448 & 434 & 420 & 406 & DPEP Series \\
\hline$\cdots$ & 100 & 70.4 & 59.3 & 42.6 & 37.0 & $\cdots$ & $\cdots$ & $\cdots \cdots$ & $\cdots$ & $\cdots$
\end{tabular}

Porphyrin

\begin{tabular}{ccccccccccc}
548 & 534 & 520 & 506 & 492 & 478 & 464 & 450 & 436 & 422 & 408 \\
\hline$\cdots$ & 39.8 & 19.6 & 81.2 & 61.6 & 73 & 31.5 & 38.9 & $\ldots$ & $\cdots$ & $\cdots$
\end{tabular}

\begin{tabular}{|c|c|c|c|c|c|c|c|c|c|c|c|}
\hline & 546 & 532 & 518 & 504 & 490 & 476 & 462 & 448 & 434 & 420 & 406 \\
\hline $\begin{array}{l}\text { Polar } \\
\text { Nickel }\end{array}$ & $\cdots$ & 98.7 & 100 & 85.7 & 48.1 & 31.2 & 40.3 & $\cdots$ & $\cdots$ & $\cdots$ & $\cdots$ \\
\hline \multirow[t]{2}{*}{ Porphyrin } & 548 & 534 & 520 & 506 & 492 & 478 & 464 & 450 & 436 & 422 & 408 \\
\hline & $\cdots$ & 27.4 & 25.6 & 55.7 & 50.5 & 50.5 & 5.5 & $\cdots$ & $\cdots$ & $\cdots$ & $\cdots$ \\
\hline \multirow{2}{*}{$\begin{array}{l}\text { Vanadyl } \\
\text { Porphyrin }\end{array}$} & 555 & 541 & 527 & 513 & 499 & 485 & & & & & \\
\hline & $\cdots$ & 100 & 94.7 & 50.7 & $\cdots$ & $\cdots$ & & & & & \\
\hline
\end{tabular}

$362-11$

\begin{tabular}{lcccccc}
$\begin{array}{l}\text { Free Base } \\
\text { Porphyrin }\end{array}$ & 476 & 462 & 448 & 434 & 420 & 406 \\
\cline { 2 - 7 } & 100 & 85.1 & 80.9 & 51.1 & 38.3 & 31.9
\end{tabular}

$364-41$

\begin{tabular}{|c|c|c|c|c|c|c|c|c|c|c|c|c|}
\hline \multirow{4}{*}{$\begin{array}{l}\text { Nickel } \\
\text { Porphyrin }\end{array}$} & 546 & 532 & 518 & 504 & 490 & 476 & 462 & 488 & 434 & 420 & 406 & DPEP Series \\
\hline & 16.7 & 100 & 54.2 & 60.4 & 31.3 & 25.0 & 16.7 & 14.6 & $\cdots$ & $\cdots$ & $\cdots$ & \\
\hline & 548 & 534 & 520 & 506 & 492 & 478 & 464 & 450 & 436 & 422 & 408 & etio Series \\
\hline & 10.3 & 14.1 & 12.8 & 35.5 & 40.3 & 73.8 & 45.6 & 48.6 & 31.3 & 16.7 & $\cdots$ & \\
\hline \multirow{4}{*}{$\begin{array}{l}\text { Polar } \\
\text { Nickel } \\
\text { Porphyrin }\end{array}$} & 546 & 532 & 518 & 504 & 490 & 476 & 462 & 448 & 434 & 420 & 406 & \\
\hline & $\cdots$ & 57.2 & 100 & 82.1 & 89.3 & 64.3 & $\cdots$ & $\cdots$ & $\cdots$ & $\cdots$ & $\cdots$ & \\
\hline & 548 & 534 & 520 & 506 & 492 & 478 & 464 & 450 & 436 & 422 & 408 & \\
\hline & $\cdots$ & 21.1 & 26.3 & 40.1 & 37.4 & 61.3 & 71.4 & 75.0 & $\cdots$ & $\cdots$ & $\cdots$ & \\
\hline
\end{tabular}


TABLE 2 - Continued

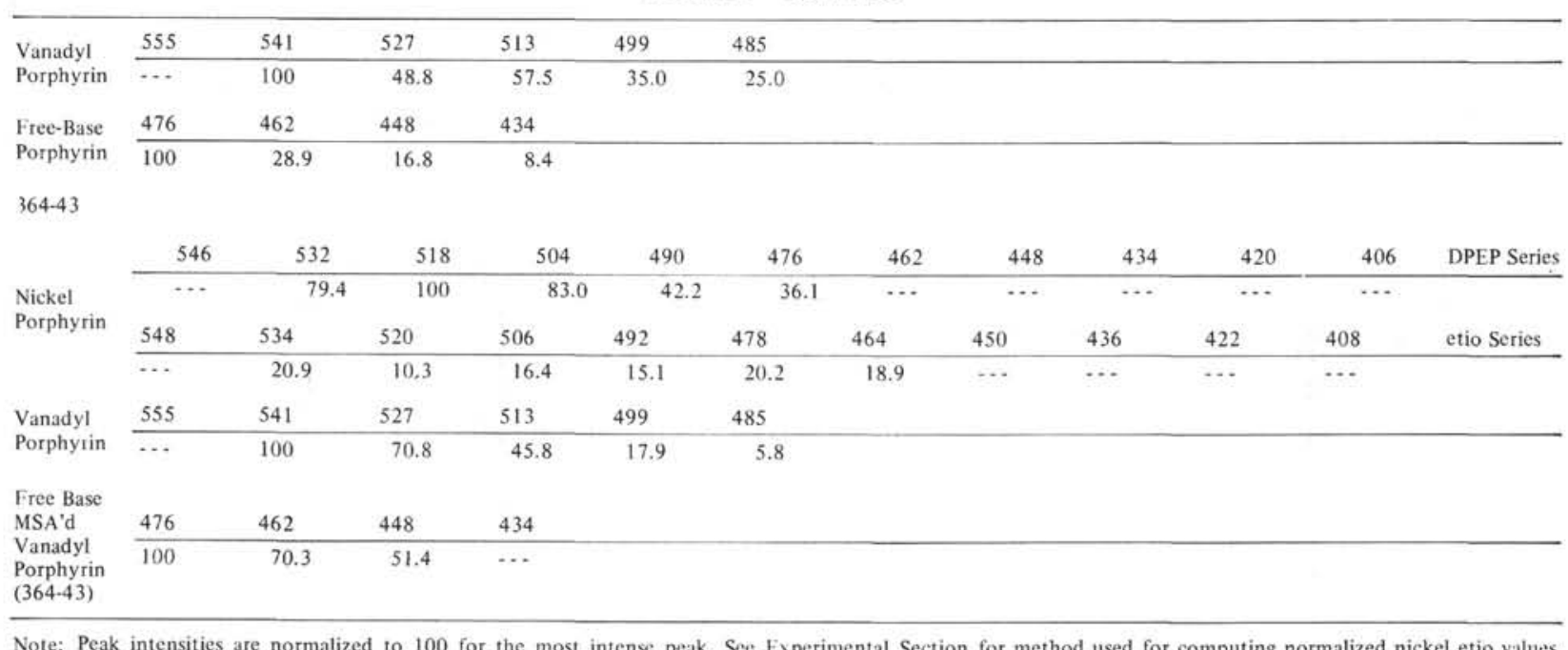

these pigments are given in Table 1. Total pigment yields of four Site 361 extracts averaged $0.73 \mu \mathrm{g} / \mathrm{g}$, while yields from two samples of the same age or depth of burial from Site 364 ranged from 3.8 to $130 \mu \mathrm{g} / \mathrm{g}$ of wet sediment. In contrast, Core 363-39, also of early Cretaceous age, contained only nickel porphyrin in small amounts $(0.02 \mu \mathrm{g} / \mathrm{g})$. We now present a systematic discussion of these data.

\section{Free Base Porphyrins}

In the present suite of samples (See Table 1) free base porphyrins were found in association with chlorins in Pleistocene and Pliocene sediments and with vanadyl and nickel porphyrins in Cretaceous sediments (for previous reports of free base porphyrins see Baker and Smith, 1975a; Baker et al., 1976). Note that this is the first report of the combination of vanadyl porphyrins and free base porphyrins.

The fraction of free base porphyrins in Cretaceous samples ranged from a nondetectable amount to about $33 \%$ in $364-41$. Free base porphyrins were associated with chlorins to the maximum extent of $25 \%$ in $362-11$.

The electronic and mass spectra show that only DPEP and its homologs were present with etio series being entirely absent. Further, no transalkylated free base porphyrins were present and thus the homologous series has a truncated distribution rather than the petroporphyrin-type Gaussian distribution (Baker et al., 1967). Figure 1 shows a selected portion of the $14 \mathrm{ev}$ mass spectrum of the free base porphyrin fraction of $364-41$. It is suspected that the peak at $\mathrm{m} / \mathrm{e} 488$ is a nonporphyrin material and as such has not been included in the calculations.

\section{Nickel Porphyrins}

Only in the nickel porphyrin fractions were porphyrins of the etio series observed. In this case, two homologous series of porphyrins (DPEP and etio) plus the bi-isotopic metal leads to a mass spectrum much more complex in appearance than that of the vanadyl porphyrins (compare Figures 2 and 3). Deconvolution procedures are described in the Experimental Section.
Various parameters describing the molecular weight distributions of the nickel porphyrins are presented in Table 3. The DPEP/etio ratio varies from about 3 to 0.5 , with 0.5 being an unusually low value. The average weighted mass for the etio series is always lower than for the corresponding DPEP series. But, because of the bimodal nature of some of these sample distributions (Table 2), the modal value for the DPEP series is not always higher than that of the etio series. Quite consistently, the band width of the etio series is wider than for the DPEP series.

\section{Vanadyl Porphyrins}

In Table 2 the vanadyl porphyrin mass spectrometric data for Cores $361-31,-34,-38,-42$, and $364-41$ and -43 are presented in the usual fashion as normalized $\mathrm{m} / \mathrm{e}$ intensities. Vanadyl porphyrins comprise $20 \%$ to $85 \%$ of the total pigment present in the six samples (Table 1).

In all six samples the $\mathrm{m} / \mathrm{e} 541$ peak corresponding to a porphyrin molecular weight of 476 (identical to the nominal mass of DPEP) was the major peak. In most cases the preponderance of the vanadyl porphyrin is accounted for by the $\mathrm{m} / \mathrm{e} 541\left(\mathrm{C}_{32}\right), 527\left(\mathrm{C}_{31}\right), 513\left(\mathrm{C}_{30}\right)$. and $499\left(\mathrm{C}_{29}\right)$ peaks comparable to the free base distribution (see free base distribution data for 364-41 in Table 2).

However, in three of the six samples the homologous series is detectable downward to an $\mathrm{m} / \mathrm{e}$ of 485 corresponding to the porphyrin nucleus plus eight methylene groups $\left(\mathrm{C}_{28}\right)$. That these vanadyl porphyrins were of the DPEP series was further substantiated by demetallation of the $364-43$ fraction with MSA. A free base porphyrin mixture with a DPEP-type electronic spectrum and a mass spectrum consistent with porphyrins containing one carbocyclic ring was obtained (see Table 2).

In Figure 3 is shown a typical mass spectrum of the vanadyl porphyrin fraction isolated from organic extracts of early Cretaceous black shales (364-43). The spectrum is relatively simple when compared to the vanadyl porphyrin fraction of a typical petroleum or even that isolated from Challenger Knoll oil bearing 

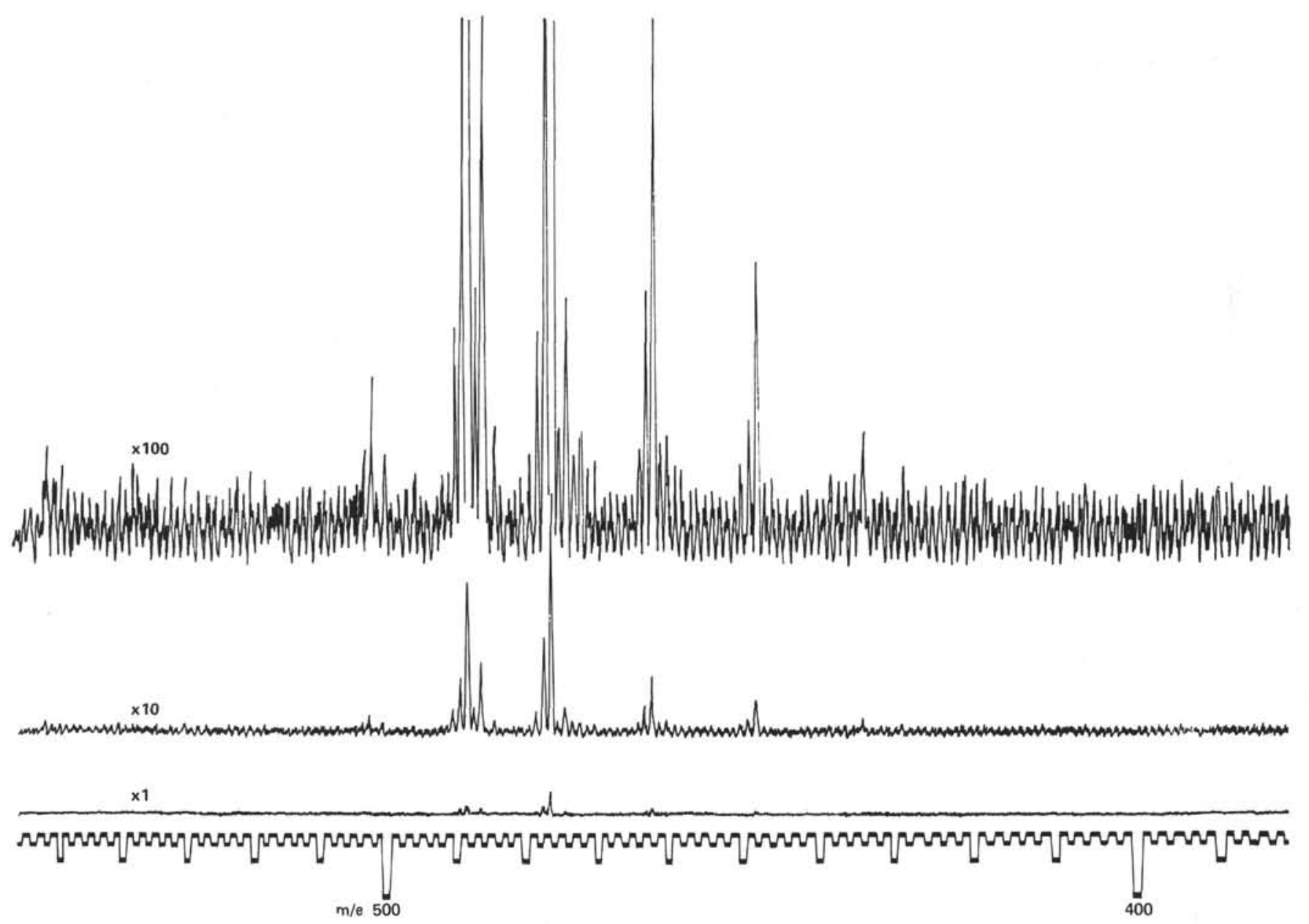

Figure 1. Partial $14 \mathrm{ev}$ mass spectrum of free-base porphyrin fraction of the organic extract from 364-41. Source and probe temperature $235^{\circ}$. Major spectral peaks are: $\mathrm{m} / \mathrm{e} 476,462$, and $448 . \mathrm{M} / \mathrm{e}=488$ is non porphyrin; see text for discussion.

cores (Baker, 1969). Further, two differences are immediately noted (1) the absence of an envelope of porphyrins of the etio series, e. g., 501, 515, 529, 543 and (2) the absence of high molecular weight porphyrins, e. g., carbon skeletons greater than $\mathrm{C}_{32}$ (M.W. of vanadyl DPEP $=541$ ).

In addition to the peaks of the vanadyl DPEP series, the mass spectrum of the $364-43$ vanadyl porphyrin fraction (Figure 3) shows a major peak at $\mathrm{m} / \mathrm{e} 553$. A vanadyl porphyrin of early Cretaceous origin with an $\mathrm{m} / \mathrm{e}$ of 553 would be most unusual since such a compound would represent an unsaturation of two hydrogen atoms greater than that of DPEP. Structural features to which such unsaturation could be ascribed would be either an unreduced vinyl group or an additional carbocyclic ring. Neither feature seems probable: The first, because vinyl groups are expected to be reduced at an early stage of diagenesis with unlikely survival into the Cretaceous and the second, because fused rings are inherently highly strained. That the $\mathrm{m} / \mathrm{e} 553$ peak does not represent a vanadyl porphyrin was demonstrated by the following: (1) demetallation with MSA produced porphyrins with $\mathrm{m} / \mathrm{e}$ values $=476,462$, and 448 (Table $2,364-43$ ) with the same peak intensity ratios as the 541,527 , and 513 peaks of the vanadyl porphyrins from which they were derived (Table 2) and (2) attempts to devinylate the compound having $\mathrm{m} / \mathrm{e}=553$ with resorcinol were negative as were attempts to prepare hydrazones with anhydrous hydrazine.

\section{Unidentified Metalloporphyrin}

A unique metalioporphyrin was found in small amounts (less than $1 \%$ of total pigment) in samples from Site 364. It was eluted only after large volumes of THF were applied to the Sephadex LH 20 column and was very polar, only eluting with methanol from Alumina Grade III columns.

Initially, because of spectrophotometric characteristics (Figure 4), this pigment was thought to be a polar vanadyl porphyrin, perhaps containing a carboxyl group. After treatment with diazomethane, no change in chromatographic behavior on Alumina was observed, ruling out the presence of a carboxyl group. Complexing the pigment with pyridine failed to give a 2-branched Soret which eliminated nickel, vanadyl, and magnesium as the possible metals in this particular pigment (Corwin et al., 1963). Chelation of naturally occurring free base porphyrin of the DPEP series with zinc yielded a material with a UV-visible spectrum 


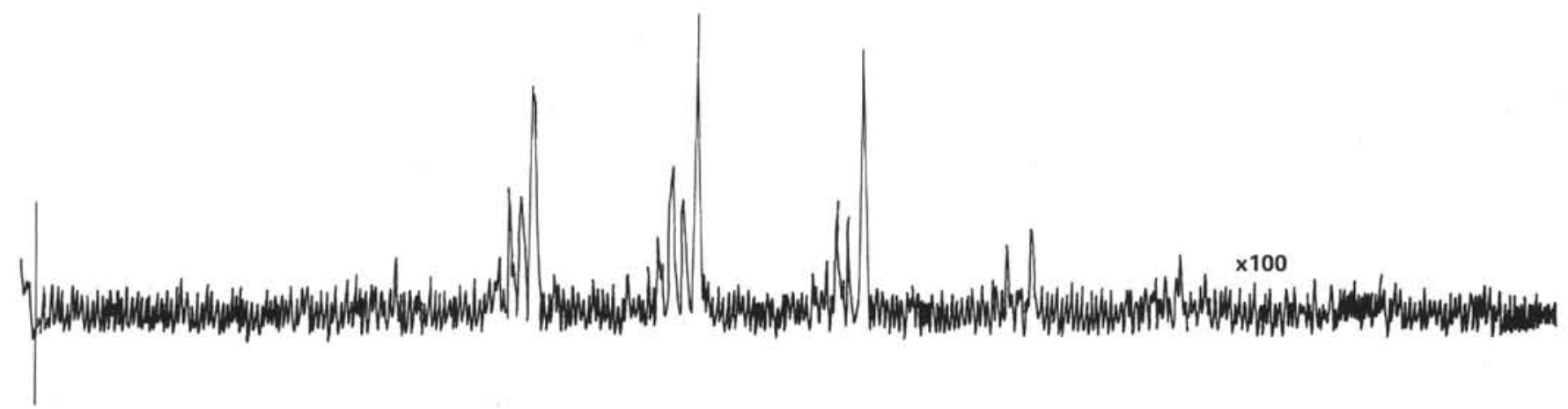

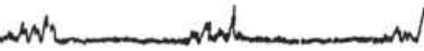

久. $\times 10$

x1

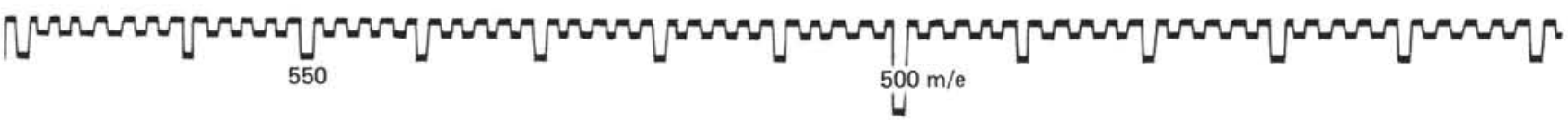

Figure 2. Partial $14 \mathrm{ev}$ mass spectrum of the nickel porphyrin fraction of the organic extract from $364-43$. Source and probe temperature $250^{\circ}$. Major spectral peaks are: m/e 532, normalized intensity $=76, \mathrm{C}_{32} \mathrm{H}_{34} \mathrm{~N}_{4} \mathrm{Ni} \mathrm{i}^{58} ; \mathrm{m} / \mathrm{e} 518$, normalized intensity $=100, \mathrm{C}_{31} \mathrm{H}_{32} \mathrm{~N}_{4} \mathrm{Ni}{ }^{58} ; \mathrm{m} / \mathrm{e} 504$, normalized intensity $=88, \mathrm{C}_{30} \mathrm{H}_{30} \mathrm{~N}_{4} \mathrm{Ni}{ }^{58}$; and m/e 490, normalized intensity $=29, \mathrm{C}_{29} \mathrm{H}_{28} \mathrm{~N}_{4} \mathrm{Ni}$.
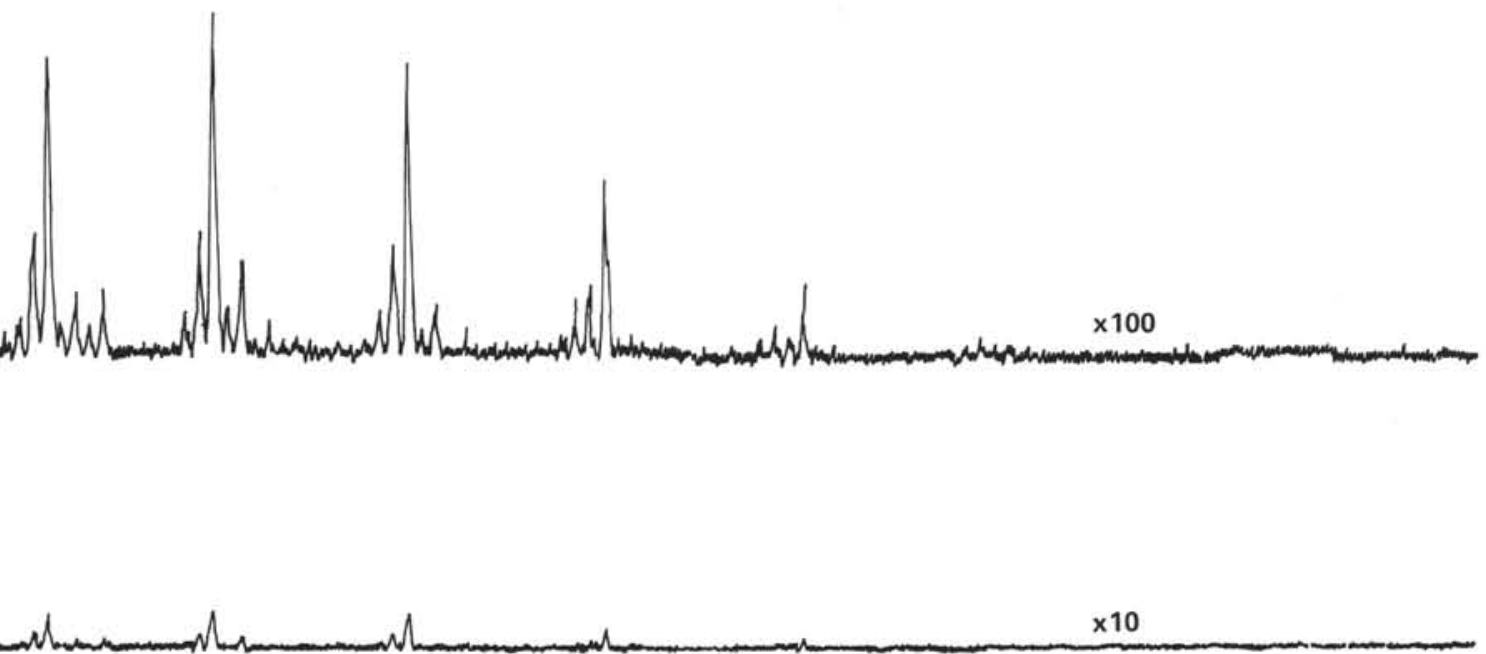

$x 10$

$x 1$

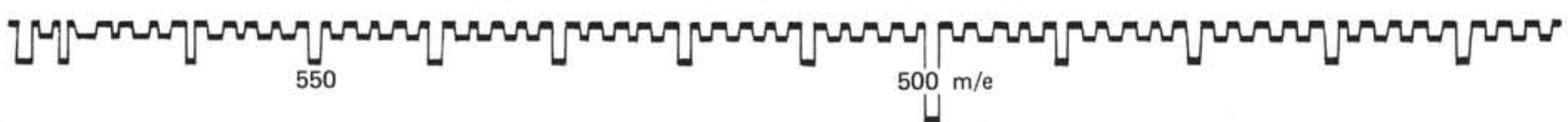

Figure 3. Partial $14 \mathrm{ev}$ mass spectrum of the vanadyl porphyrin fraction of the organic extract 364-43. Source and probe temperature $265^{\circ}$. Major spectral peaks are: m/e 541, normalized intensity $=100, \mathrm{C}_{32} \mathrm{H}_{34} \mathrm{~N}_{4} \mathrm{VO} ; \mathrm{m} / \mathrm{e} 527$, normalized intensity $=83, \mathrm{C}_{31} \mathrm{H}_{32} \mathrm{~N}_{4} \mathrm{VO} ; \mathrm{m} / \mathrm{e} \mathrm{513}$, normalized intensity $=46, \mathrm{C}_{30} \mathrm{H}_{30} \mathrm{~N}_{4} \mathrm{VO} ;$ and m/e $=499$, normalized intensity $=$ 20, $\mathrm{C}_{29} \mathrm{H}_{28} \mathrm{~N}_{4} \mathrm{VO} . \mathrm{M} / \mathrm{e} 553$ is non porphyrin, see text for details. 
TABLE 3

Molecular Weight Distribution Parameters of Nickel Porphyrins Isolated From Early Cretaceous Core Samples, Sites 361 and 364

\begin{tabular}{|c|c|c|c|c|c|c|c|}
\hline \multirow[b]{2}{*}{ Core } & \multirow{2}{*}{$\frac{\text { DPEPEI }}{\text { etiozI }}$} & \multicolumn{2}{|c|}{ Weighted A verage Mass } & \multicolumn{2}{|c|}{ Mode } & \multicolumn{2}{|c|}{ Band Width } \\
\hline & & $\overline{\mathrm{x}}$ DPEPa & $\bar{X}$ etio $^{a}$ & $M_{o}$ DPEPb & $\mathrm{M}_{\mathrm{o}} \mathrm{etio}^{\mathrm{b}}$ & ${ }_{a}$ DPEPC & octio $^{\mathrm{c}}$ \\
\hline $361-31$ & 2.1 & 487 & 481 & 476 & 492 & 36.5 & 37.2 \\
\hline $361-34$ & 1.4 & 500 & 485 & 532 & 506 & 28.5 & 25.0 \\
\hline $\begin{array}{l}361-38 \\
361-38 \\
\text { (polar) }\end{array}$ & $\begin{array}{l}0.54 \\
0.67\end{array}$ & $\begin{array}{l}532 \\
517\end{array}$ & $\begin{array}{l}506 \\
491\end{array}$ & $\begin{array}{l}532 \\
532\end{array}$ & $\begin{array}{l}506 \\
478\end{array}$ & $\begin{array}{l}11.7 \\
14.9\end{array}$ & $\begin{array}{l}25.2 \\
24.7\end{array}$ \\
\hline $\begin{array}{l}361-42 \\
361-42 \\
\text { (polar) }\end{array}$ & $\begin{array}{l}0.9 \\
1.9\end{array}$ & $\begin{array}{l}510 \\
506\end{array}$ & $\begin{array}{l}491 \\
500\end{array}$ & $\begin{array}{l}532 \\
518\end{array}$ & $\begin{array}{l}506 \\
506\end{array}$ & $\begin{array}{l}19.5 \\
21.7\end{array}$ & $\begin{array}{l}24.8 \\
20.5\end{array}$ \\
\hline $\begin{array}{l}364-41 \\
364-41 \\
\text { (polar) }\end{array}$ & $\begin{array}{l}0.95 \\
1.28\end{array}$ & $\begin{array}{l}507 \\
504\end{array}$ & $\begin{array}{l}474 \\
480\end{array}$ & $\begin{array}{l}532 \\
518\end{array}$ & $\begin{array}{l}478 \\
450\end{array}$ & $\begin{array}{l}25.2 \\
18.9\end{array}$ & $\begin{array}{l}29.2 \\
28.3\end{array}$ \\
\hline $364-43$ & 3.35 & 510 & 498 & 518 & 534 & 18.0 & 26.2 \\
\hline
\end{tabular}

${ }^{\mathrm{a}}$ Corresponds to the weighted average mass, obtained by $\mathrm{\Sigma}$ IM/ $\mathrm{\Sigma} 1$ from Table 2, where $\mathrm{M}$ is the mass and $I$ is the intensity.

${ }^{b}$ Obtained from Table 2; $\mathrm{I}$ is the intensity and $\mathrm{M}_{\mathrm{O}}$ the mode of the molecular weight distribution.

CThe band width is giveras the standard deviation $(\sigma)$ in mass units, computed according to the formula $a=\sqrt{\Sigma\left(\mathrm{IM}^{2}\right) / \Sigma I-(\Sigma I M / \Sigma I)^{2}}$ where $\mathrm{I}$ is the intensity and $\mathrm{M}$ the mass, both taken from Table 2

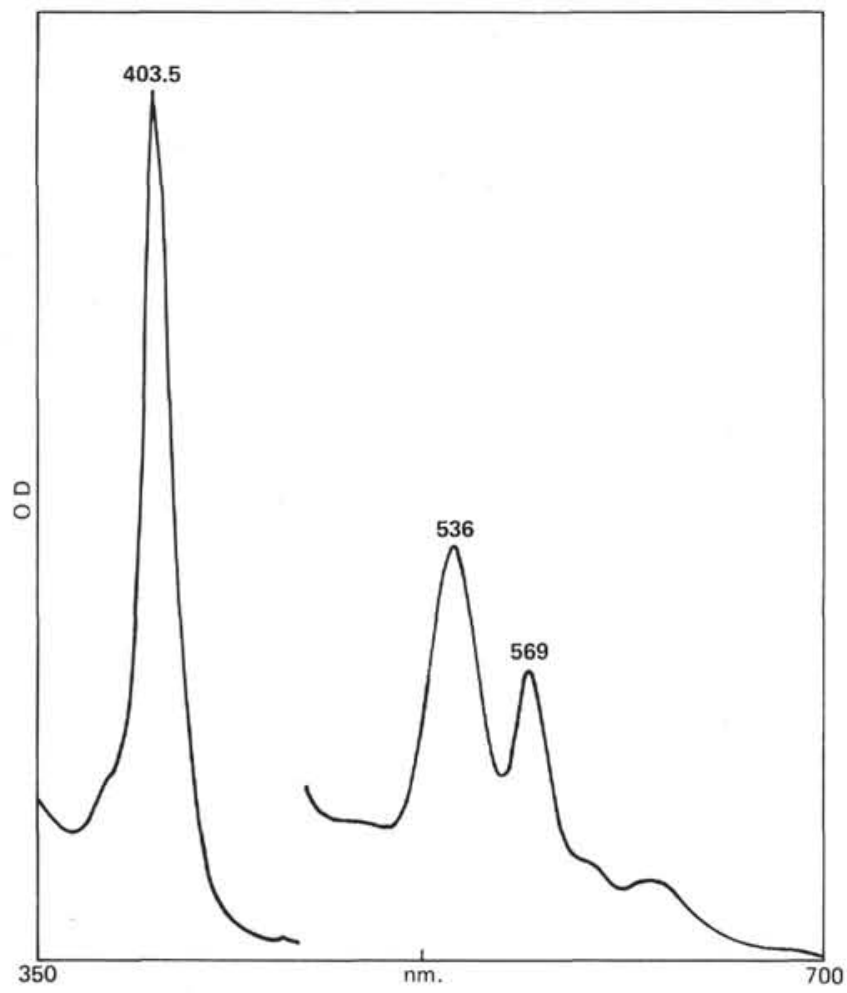

Figure 4. UV-visible spectrum of unidentified metalloporphyrin isolated from organic extract of 364-43. See text for details.

remarkably similar to that of the unknown pigment shown in Figure 4. Comparison of fluorescence between the prepared zinc chelates and the unknown were positive. However, the zinc chelates of alkyl porphyrins have polarities similar to those of vanadyl chelates with the same ligand and much lower polarities than the unknown. Thus, our present data suggest that the unknown pigment is a zinc chelate of a polar porphyrin. Mass spectrometric analyses are incomplete.

\section{SUMMARY AND CONCLUSIONS}

DSDP Leg 40 provided a suite of samples which yielded pigments representing early to mid diagenetic stages of the chlorophyll molecule. Chlorins were found in Pleistocene and Tertiary sediments while free base and metalloporphyrins characterized early Cretaceous strata.

Chlorin fractions from Pleistocene through Miocene (Site 362) and Eocene (Site 361) sediments displayed several features: (1) two major groupings based on chromatographic behavior and electronic spectra were found whose red bands (661-658 nm) and Soret bands $(407.5-400 \mathrm{~nm})$ shifted to lower wavelengths with increasing depth of burial, (1) a decrease in concentration of the total chlorin coupled with an increase in the late-running Sephadex fraction relative to the firstrunning fraction with increasing depth/age, (3) the presence of chlorins in two cores with long wavelength red bands ( 680 and $690 \mathrm{~nm}$ ) indicative of deep-seated molecular changes, and (4) the presence of chlorins in two cores with relatively short wavelength red bands (641 and $643 \mathrm{~nm}$ ) possibly indicative of metallochlorins. Free base porphyrins of the DPEP series were found with chlorins in sediments of early Pleistocene and of Pliocene age.

Free base porphyrins and vanadyl porphyrins of the DPEP series were found in early Cretaceous sediments (Sites 361 and 364). Molecular weight distributions of these two groups of porphyrins yield truncated homologous series (Table 2). In contrast, nickel porphyrins also present in these sediments in some cases displayed a bimodal molecular weight distribution of the etio and DPEP series.

The components of tetrapyrrole mixtures isolated from early Cretaceous samples have been separated and purified to the extent that high quality spectra (mass and electronic) could be obtained. Analyses of the individual porphyrin components rather than the total demetallated mixture (as done previously, Baker, et al., 1967) yield important new information concerning the state of diagenesis. Specifically, the observation of the molecular weight distributions of the various components permits determination of whether or not the total mixture has undergone the same amount of thermal stress. Such information can also aid in defining the nature and degree of complexity of the source of organic material. Extreme differences in the molecular weight distributions of the components of porphyrin mixtures is a possible indicator of recycled material.

Certain conclusions may be drawn from these data. It is likely that reworking of Site 361 early Cretaceous sediments (Cape Basin) and the presence of a mixture of continental and marine-derived material, are related to the randomness observed in the DPEP/etio ratios, modal values, and band widths shown in Table 3 (Leg 40 Site Summary). The observed intermixed populations of nickel porphyrins having different polarities and producing bimodal distributions (Table 2) found in this suite of sediment samples may be a result of lithological makeup. This conclusion is further supported by the low DPEP/etio ratios $(0.54$ and 0.67$)$ observed for nickel porphyrins from Core 361-38. 
In a mixture of vanadyl and nickel porphyrins, which have undergone thermal treatment, one would expect to find porphyrins of the etio series in both. Comparison with other samples (Baker, et al., 1967) of known thermal history suggests that the centroid for the nickel etio series would be shifted by dealkylation to a value corresponding to $\mathrm{C}_{30}$ or lower (e.g., 506), and a vanadyl etio series would begin to appear (at m/e 529 and 515). No such series was observed in any of the vanadyl porphyrins reported here (Table 2). Therefore, it appears that the total porphyrin mixture in Core 36138 (vanadyl, "polar," and "nonpolar" nickel porphyrins) has not undergone the same thermal treatment. This is best examplified by the "polar" nickel fraction (see Table 2, Core 361-38) which has a large contribution of highly dealkylated porphyrins of the etio series having $\mathrm{m} / \mathrm{e}=478,464$, and $450\left(\mathrm{C}_{28}, \mathrm{C}_{27}\right.$, and $\mathrm{C}_{26}$ ). Such a degree of dealkylation is indicative of severe thermal stress or possibly oxidation. Therefore, nickel porphyrins of this group likely result from the incorporation of reworked thermally stressed material or oxidized terrestrial material into a population of porphyrins with a mild thermal history. The absence of transalkylated vanadyl porphyrins $\left(\mathrm{C}_{33}\right.$ and greater) such as that found in Challenger Knoll oil lends further support to this premise.

Samples from the Angola Basin (Site 364) of the same age and depth are remarkably similar (as expected) to those from the Cape Basin (Site 361). The lithologic findings indicating a high degree of mixing in the Cape Basin agree with the geochemistry reported herein. With respect to the Angola Basin where the lithological reports are less detailed, we suggest the following: some input of material such as described for Site 361 samples into Core $364-43$ and substantial input into Core 364-41. Our data suggests that the native material in the Angola Basin has the potential of being source rock but that it is not sufficiently mature. Based on total pigment yield, Core $361-41$ contains 30 to 40 times more pigment than Core $361-43$ which in itself suggests that 361-41 would have a higher rating as a source rock. On the other hand, our nickel porphyrin data also suggest that Core $364-41$ contains a larger proportion of thermally stressed material than does Core 364-43. The organic carbon data (Table 1) indicate that Cores $364-41$ and -43 both contain high amounts of organic matter. Our data, obtained from only one segment from each of these cores, suggest that, on the basis of amount of reworked material, Core 364-
43 would be the better source rock. This conclusion assumes that the ratios of the individual tetrapyrrole components remain constant and that the analyses reported here are representative throughout the length of both cores.

\section{ACKNOWLEDGMENTS}

This research was supported by the Oceanography Section of the National Science Foundation, Grants GA-43359X and DES-74-12438 A01.

\section{REFERENCES}

Baker, E.W., 1969. Porphyrins. In Ewing, M., Worzel, J.L, et al., Initial Reports of the Deep Sea Drilling Project, Volume 1: Washington (U.S. Government Printing Office), p. 498.

Baker, E.W., Palmer, S.E., and Parrish, K.L., 1976. Tetrapyrrole pigments in DSDP Leg 38 Sediments. In Talwani, M., Udintsev, G., et al., Initial Reports of the Deep Sea Drilling Project, Volume 38: Washington (U.S. Government Printing Office), p. 785 .

Baker, E.W. and Smith, G.D., 1973a. Chlorophyll derivaties in sediments, Site 147. In Heezen, B.C., MacGregor, I., et al., Initial Reports of the Deep Sea Drilling Project, Volume 20: Washington (U.S. Government Printing Office), p. 943.

1973b. Pleistocene Changes in Chlorophyll Pigments. In Tissot, B. and Bienner, F., (Eds.), Paris (Editions Technip), p. 649. 1975a. Chlorophyll derivatives in DSDP Leg 31 sediments. In Ingle, J.C., Karig, D.E., et al., Initial Reports of the Deep Sea Drilling Project, Volume 31: Washington (U.S. Government Printing Office), p. 629. 1975b. Chlorophyll derivatives in DSDP Leg 14, 20, 26, 27 and 29 sediments. In Ingle, J.C., Karig, D.E., et al., Initial Reports of the Deep Sea Drilling Project, Volume 31: Washington (U.S. Government Printing Office), p. 905.

Baker, E.W., Yen, T.F., Dickie, J.P., Rhodes, R.E., and Clark, L.F., 1967. Mass spectrometry of Porphyrins II: Characterization of petroporphyrins: J. Am. Chem. Soc., v. 89, p. 3631 .

Corwin, A.H., Whitten, D.G., Baker, E.W., and Kleinspehn, G.G., 1963. Steric Effects of the near-ultraviolet absorption (Soret Band) of porphyrins: J. Am. Chem. Soc., v. 85 , p. 3621 .

Smith, G.D. and Baker, E.W., 1974. Chlorophyll derivatives in DSDP Leg 22 sediments. In von der Borch, C.C., Sclater, J.G., et al., Initial Reports of the Deep Sea Drilling Project, Volume 22: Washington (U.S. Government Printing Office), p. 677. 